\title{
PATTERN OF BACTERIAL ISOLATES CAUSING NEONATAL SEPTICEMIA ALONG WITH THEIR PATTERN OF ANTIBIOTIC SUSCEPTIBILITY.
}

\footnotetext{
1. FCPS (Pediatrics Medicine) Assistant Professor Pediatrics Sheikh Khalifa Bin Zaid AI Nahyan Teaching Hospital, Rawlakot

2. MBBS, FCPS (Pead)

PGR Pediatric Medicine The Children's Hospital and The Institute of Child Health, Multan

3. FCPS (Pediatrics Medicine) Assistant Professor Pediatrics Medicine

Ghurki Trust Teaching Hospital, Lahore.

4. FCPS (Pediatrics Medicine) Fellow in Pediatrics Neurology Agha Khan Hospital, Karachi.
}

Correspondence Address: Dr. Fazal Ur Rehman

Pediatric Medicine

The Children's Hospital and

The Institute of Child Health, Multan

fazal171@gmail.com

Article received on 06/04/2019

Accepted for publication: 27/08/2019

\begin{abstract}
Shahid Iqbal' ${ }^{1}$, Fazal Ur Rehman², Waqas $\mathrm{Ali}^{3}$, Sanam Bano Rajper ${ }^{4}$
ABSTRACT... Objectives: We planned this study to observe the pattern related to bacterial isolates causing neonatal septicemia along with their pattern of antibiotic susceptibility. Study Design: Prospective study. Setting: Department of Neonatology, Sheikh Khalifa Bin Zaid Al Nahyan Teaching Hospital, Rawlakot. Period: From $1^{\text {st }}$ January 2018 to $30^{\text {th }}$ June 2018. Material \& Methods: Prior to empiric antibiotic usage, blood was collected from neonates having clinical sepsis and sent for blood culture. A total of 60 neonates with culture proven sepsis were enrolled for this study. Reports of blood culture were evaluated for isolates of bacteria as well as patterns of sensitivity for frequently used antibiotics in the institution. SPSS version 21.0 was used for data entry and analysis. Results: A total of 60 neonates having culture proven sepsis were enrolled in the current study. Amongst these, 39 (65.0) were male and $21(35.0 \%)$ female. Early onset of sepsis was diagnosed in most, 42 (70.0\%) neonates. Majority of neonates, 50 (83.3\%) were delivered in the same hospital. Gram negative isolates were found in 43 (71.7\%) and $15(25.0 \%)$ gram positive while $2(3.3 \%)$ candida spp. In terms of pattern of antibiotic sensitivity, $4(9.3 \%)$ isolates of gram negative were found resistant to every antibiotic routinely used while gram positive isolates showed excellent sensitivity to vancomycin. Conclusion: Gram negative isolates of organisms were found to be the most sensitive to carbepenems (especially meropenem) as well as aminoglycosides while gram positive isolates showed excellent sensitive regarding vancomycin.

Key words: $\quad$ Antibiotics, Bacterial Isolates, Blood Culture, Neonatal Sepsis.

Article Citation: Iqbal S, Fazal Ur Rehman, Ali W, Rajper SB. Pattern of bacterial isolates causing neonatal septicemia along with their pattern of antibiotic susceptibility. Professional Med J 2020; 27(4):737-741.

DOI: 10.29309/TPMJ/2020.27.04.3524
\end{abstract}

\section{INTRODUCTION}

Neonatal sepsis is described as bacterial infection noted by positive blood culture during the $1^{\text {st }} 4$ weeks of life. It is estimated to be one of the leading contributors of neonatal deaths in our region. ${ }^{1-3}$ The $\mathrm{WHO}$ notes neonatal sepsis as a major contributor of neonatal mortality and an incidence of 1-10 out of 1000 live births amongst developing countries. These figures seem to rise nearly 3 times when we consider the numbers from Pakistan. ${ }^{4}$ Around the world, rates of infection are thought to be as indicators of quality as well as safety in the healthcare vicinities. ${ }^{5}$

Diagnosis of neonatal septicemia is considered to be a difficult task and most of the times, neonates are presenting with signs and symptoms that are non-specific. Blood culture for isolation of culprit pathogen is considered to be the gold standard for confirmed diagnosis regarding sepsis. ${ }^{6}$

A common approach by most clinicians is adopted by starting empiric antibiotic therapy involving an antibiotic of broad spectrum in neonates who are suspected to have bacterial infection. ${ }^{7,8}$ Organisms responsible for neonatal septicemia vary region to region or even can differ in healthcare facilities of a same region. Gram negative microorganisms are documented to be the most frequent cause of neonatal septicemia among developing countries. ${ }^{9,10}$ It has also been seen that organisms may go on to substitute others over a span of time. Knowledge about the susceptibility patterns of antimicrobials against the common pathogens in an area while dealing neonatal septicemia is most important 
while choosing an empirical therapy. So, we planned this study to observe the pattern related to bacterial isolates causing neonatal septicemia along with their pattern of antibiotic susceptibility.

\section{MATERIAL AND METHODS}

This prospective study was conducted at Department of Neonatology, Sheikh Khalifa Bin Zaid Al Nahyan Teaching Hospital, Rawlakot, from $1^{\text {st }}$ January 2018 to $30^{\text {th }}$ June 2018. Approval from ethical committee of the institute was taken for this study. Consent was granted from parents / guardians of all the participants.

Prior to empiric antibiotic usage, blood was collected from neonates having clinical sepsis using peripheral vein staying under strict aseptic conditions, inoculated into brain-heart infusion broth and then sent to institution's microbiology laboratory for blood culture. A total of 60 neonates with culture proven sepsis were enrolled for this study. Neonatal septicemia was categorized as either early-onset sepsis ( $<72$ hours) or lateonset sepsis (>72 hours). ${ }^{9}$ Reports of blood culture were evaluated for isolates of bacteria as well as patterns of sensitivity for frequently used antibiotics in the institution. Disk-diffusion method was adopted to assess the sensitivity to frequently used antibiotics. SPSS version 21.0 was used for data entry and analysis.

\section{RESULTS}

A total of 60 neonates having culture proven sepsis were enrolled in the current study. Amongst these, 39 (65.0) were male and 21 (35.0\%) female. Early onset of sepsis was diagnosed in 42 (70.0\%) while late onset sepsis in 18 (30.0\%). There were $50(83.3 \%)$ neonates who were delivered in the same hospital whereas 10 (16.7\%) were out-born.

When bacterial isolates among these neonates were assessed, gram negative were found in $43(71.7 \%)$ and $15(25.0 \%)$ gram positive while 2 (3.3\%) candida spp. Gram negative bacteria were further divided as 28/43 (65.1\%) citrobacter, 6/43 (14.0\%) acinetobacter, 5/43 (11.6\%) pseudomonas, 2/43 (4.7\%) klebsiella and unclassified as 2/43 (4.7\%). As far as gram positive isolates are concerned, we found all 15 cases having staphylococcus aureus. (Table-I)

In terms of pattern of antibiotic sensitivity, 4 (9.3\%) isolates of gram negative were found resistant to every antibiotic routinely used (amplicillin, cefotaxime, ceftazidime, amikacing, meropenam, cefixime and cefipime). Detailed description regarding patterns of antimicrobials susceptibility of blood culture isolates is detailed in Table-II.

\begin{tabular}{|c|c|c|}
\hline \multicolumn{2}{|c|}{ Isolates } & No. (\%) \\
\hline \multicolumn{2}{|l|}{ Citrobacter } & 28 (65.1\%) \\
\hline \multicolumn{2}{|l|}{ Acinetobacter } & $6(14.0 \%)$ \\
\hline \multicolumn{2}{|l|}{ Pseudomonas } & $5(11.6 \%)$ \\
\hline \multicolumn{2}{|l|}{ Klebsiella } & $2(4.7 \%)$ \\
\hline \multicolumn{2}{|l|}{ Unclassified } & $2(4.7 \%)$ \\
\hline \multicolumn{2}{|c|}{ Staphylococcus Aureus } & 15 (25.0\%) \\
\hline \multicolumn{2}{|l|}{ Candida spp } & 2 (3.3\%) \\
\hline \multicolumn{3}{|c|}{ Table-I. Isolates found in blood culture $(n=60)$. } \\
\hline Antimicrobials & $\begin{array}{c}\text { Gram -ve No. } \\
(\%)\end{array}$ & $\begin{array}{c}\text { Gram + ve No. } \\
(\%)\end{array}$ \\
\hline Ampicillin & $0(0 \%)$ & $1(6.7 \%)$ \\
\hline Augmentin & $0(0 \%)$ & $3(20.0 \%)$ \\
\hline Amikacin & $7(16.3 \%)$ & $2(13.3 \%)$ \\
\hline Meropenem & $13(30.2 \%)$ & $3(20.0 \%)$ \\
\hline Imipenem & $3(7.0 \%)$ & $3(20.0 \%)$ \\
\hline Vancomycin & --- & $15(100.0 \%)$ \\
\hline Cefixime & $5(11.6 \%)$ & $2(13.3 \%)$ \\
\hline Cefipime & $2(4.7 \%)$ & $3(20.0 \%)$ \\
\hline Ceftriaxone & $3(7.0 \%)$ & $3(20.0 \%)$ \\
\hline Erythromycin & $0(0 \%)$ & $2(13.3 \%)$ \\
\hline Clarithromycin & $0(0 \%)$ & $3(20.0 \%)$ \\
\hline Azithromycin & $0(0 \%)$ & $2(13.3 \%)$ \\
\hline Aztreonam & $6(14.0 \%)$ & ---- \\
\hline Cephradine & $0(0 \%)$ & 2 (20.0\%) \\
\hline Gentamicin & $3(7.0 \%)$ & $0(0 \%)$ \\
\hline Ciprofloxacin & $3(7.0 \%)$ & $1(6.7 \%)$ \\
\hline Norfloxacin & $2(4.7 \%)$ & $0(0 \%)$ \\
\hline Enoxacin & $2(4.7 \%)$ & $0(0 \%)$ \\
\hline Tobramycin & $2(4.7 \%)$ & $0(0 \%)$ \\
\hline Cefoperazone & $2(4.7 \%)$ & $3(20.0 \%)$ \\
\hline Resistant to all & $4(9.3 \%)$ & $0(0 \%)$ \\
\hline
\end{tabular}




\section{DISCUSSION}

Blood infections are considered to be one of the commonest reasons behind neonatal mortality. ${ }^{11}$ Frequent surveys covering aetiological patterns and their sensitivity regarding various antibiotics can certainly help finding better management options in a particular area. Antibiotic resistance has been a topic of debate and it is certainly attracting more attention in the recent decades. The course of septicaemia is quite swift and fulminant usually so a rapid management approach is required to reduce the burden of morbidity and mortality. ${ }^{12}$

In the present study, early onset of sepsis was diagnosed in majority of neonates, 42 (70.0\%). Early onset of sepsis forms the major chunk of neonatal septicemia as has been found by Sawhney $\mathrm{N}$ et $\mathrm{al}^{13}$ where they found that $57 \%$ of neonates presented with early onset sepsis. A local study done by Basheer $A$ et $\mathrm{al}^{10}$ found very similar results where they found $76 \%$ of neonates having early onset of sepsis. On the contrary, Samaga MP ${ }^{14}$ from India and few other studies $^{15,16}$ found late onset of sepsis being the predominant type of sepsis amongst neonates. It has been observed that unhygienic practices during labour and delivery or in the neonatal ICUs could be the source of thse infections especially when we consider predominant contribution of early onset of sepsis in Pakistan. ${ }^{10}$ Possible colonization of birth canal of the mother with pathogens is thought to be another reason causing early onset of neonatal sepsis. Group-B streptococcus, E. coli and coagulase negative staphylococcus are found to be involved in early onset of neonatal sepsis whereas late onset of sepsis is frequently because of healthcare settings and is mostly accompanied with coagulasen negative staphylococcus, S. aureus, E. Coli as well as klabsiella and pseudomonas. Group B streptococci as well as anaerobes and some candida are also linked with late onset of sepsis. ${ }^{17}$ Host factors like cellular immunity along with humoral immunity as well as barrier functions also play very important role that predispose newborns when we consider the factors involving neonatal sepsis. ${ }^{10}$
In the current study, we had 39 (65.0) male and $21(35.0 \%)$ female neonates. Septicemia has been found to be more common among male neonates and our findings were quite similar to many other studies conducted earlier. ${ }^{18-22}$

The results of our study showed that gram negative isolates were found in 43 (71.7\%) neonates and $15(25.0 \%)$ gram positive while 2 (3.3\%) candida spp. Gram negative bacteria, when further divided, were as 28/43 (65.1\%) citrobacter, 6/43 (14.0\%) acinetobacter, 5/43 (11.6\%) pseudomonas, 2/43 (4.7\%) klebsiella and unclassified as 2/43 (4.7\%). As far as gram positive isolates we concerned, we found all 15 cases having staphylococcus aureus. Basheer et $\mathrm{al}^{10}$ found very similar pattern in a local study where $74 \%$ neonates were found to have egative organisms (citrobacter 61\%, acinetobacter 16\%, $13 \%$ ) while gram +ve were noted to be in $24 \%$ (staphylococcus aureus).

Combined therapy containing parenteral aminoglycoside along with extended spectrum penicillin is often advised for the management of early onset of neonatal septicemia in western countries. These have been found to be effective versus frequently isolated organisms. ${ }^{10,22}$ Treatment targeting late onset of sepsis should focus more at organisms which are frequently isolated in a particular healthcare facility. It has been noted that strains of S. aureus create beta lactamase that is the reason why they are found to be resistant against all beta lactamase labile penicillins whereas so others have been observed to manufacture another penicillin binding protein near their cell wall that in turn support resistance regarding beta lactamase stable penicillins, cephalosporin's as well as carbapenems. ${ }^{10}$ Vancomycin is considered to be the most favorite choice for such kind of isolates as was found in the present study. ${ }^{23}$

A local study from Karachi ${ }^{24}$ found that procaine penicillin/gentamicin therapy was noted to be more efficacious in comparison to oral trimethoprim-sulfamethoxazole. The same study found ceftriaxone to be expensive and less efficacious in comparison to gentamicin/penicillin. 
It has been found in another local experience from Lahore ${ }^{10}$ that gram negative isolates turned out be resistant when observed for all commonly used antibiotics.

Diagnostic studies are usually enquired while treatment is commonly initiated for septicemia in neonates before confirmation of septicemia because the sign and symptoms in such neonates are often non-specific. Reports usually take about 36 to 48 hours where other laboratory parameters such as white blood cell count, immature to total neutrophil ratio as well as c-reactive protein can give us direction for the early diagnosis and management regarding neonatal septicemia.

As the incidence of bacterial isolates may differ in different locations and even within the same settings, identification of responsible organisms is of vital importance that can certainly help in reducing the burden of morbidity as well as mortality related to neonatal septicemia.

\section{CONCLUSION}

Gram negative isolates of organisms were found to be the most sensitive to carbepenems (especially meropenem) as well as aminoglycosides while gram positive isolates showed excellent sensitive regarding vancomycin. Further studies with bigger sample size in similar settings are needed to establish faith related to empirical antibiotic usage in most probable cases of neonatal sepsis. Copyright@ 27 Aug, 2019.

\section{REFERENCES}

1. Tsering DC, Chanchal L, Pal R. Bacteriological profile of septicaemia and the risk factor in neonates and infants in Sikkim. Journal of global infectious diseases. $2011 ; 3(1): 42-5$.

2. Jain A, Awasthi AK, Kumar M. Etiological and antimicrobial susceptibility profile of nosocomial blood stream infections in a neonatal intensive care unit. Indian journal of medical microbiology. 2007; 25:299-300.

3. Kumbar GD, Ramachandran VG, Gupta P. Bacteriological analysis of blood culture isolates from neonates in Tertiary Care Hospital in India. Journal of health population and nutrition. 2002; 20:3437.
4. Mehmood A, Rehman F, Chughtai F. A survey of infection control practices in the delivery room and nursery to investigate and control the high rate of neonatal sepsis: An experience at a secondary care hospital. JPMA. 2008; 58(5): 237.

5. Ducel G, Fabry J, Nicolle L. Prevention of hospital acquired infections. A practical guide. 2nd. Geneva, Switzerland. World Health Organization. 2002.

6. Sankar MJ. Neonatal sepsis in South Asia: Huge burden and spiralling antimicrobial resistance. BMJ 2019; 364:k5314.

7. GBD 2016. Causes of Death Collaborators. Global, regional, and national age-sex specific mortality for 264 causes of death, 1980-2016: A systematic analysis for the Global Burden of Disease Study 2016. Lancet 2017; 390:1151-210.

8. Investigators of the Delhi neonatal infection study (DeNIS) collaboration. Characterisation and antimicrobial resistance of sepsis pathogens in neonates born in tertiary care centres in Delhi, India: A cohort study. Lancet Global Health 2016; 4:e752- 60.

9. Pandita N, Wasim S, Bhat NK, Chandra V, Kakati B. Identification of the bacterial isolates in neonatal septicaemia and their antimicrobial susceptibility in a Tertiary Care Hospital in Uttarakhand, India: A retrospective study. Pandita $\mathrm{N}$ et al. Int $\mathrm{J}$ Contemp Pediatr. 2016; 3(1):200-5

10. Basheer A, Samaa A, Arif A. Pattern of microbial growth and antibiotic sensitivity on blood culture among neonates at a Tertiary Care Hospital. Pak Pediatr J 2014; 38(2): 75-8.

11. Robinson D, Kumar P, Cadichon S. Neonatal sepsis in the emergency department. Pediatr Emerg Med. 2008; $9(3): 160-8$.

12. Cohen ML. Changing patterns of infectious disease. Nature 2000 17; 406(6797):762-7.

13. Sawhney N, Shinu P, Singh VA. Bacteriological Profile and Antibiotic Susceptibility Pattern of Neonatal Septicaemia in a Tertiary Care Hospital. Int. J. Curr. Microbiol. App. Sci (2015) 4(10): 977-84.

14. Samaga MP. Prevalence of neonatal septicaemia in a tertiary care hospital in Mandya, Karnataka, India. Int J Res Med Sci. 2016 Jul; 4(7):2812-6.

15. Kayange N, Kamugisha E, Mwizamholya DL, Jeremiah S, Mshana SE. Predictors of positive blood culture and deaths among neonates with suspected neonatal sepsis in a Tertiary Hospital, Mwanza-Tanzania. BMC Pediatrics 2010; 10:39. 
16. Karambin MM, Zarkesh M. Enterobacter the most common pathogen of neonatal septicemia in Rasht, Iran. Iran J Pediatr. 2011; 21(1):83-7.

17. Klinger G, Levy I, Sirota L, et al. Epidemiology and risk factors for early onset sepsis among very-low-birth weight infants. Am J Obstet Gynecol 2009; 201(1): 38.

18. Aletayeb SM, Khosravi AD, Dehdashtian M, Kompani F, Mortazavi SM, Aramesh RM. Identification of bacterial agents and antimicrobial susceptibility of neonatal sepsis: A 54-month study in a tertiary hospital. African Journal of Microbiology Research. 2011; 5(5):528-31.

19. Cecilia CM, Mary AC, Elizabeth EG, Jonathan GL, Joanne $\mathrm{JL}$ et al. Etiology of neonatal sepsis in five urban hospitals in the Philippines. PIDSP Journal. 2011; 12:75-85.

20. Rabia S, Nusrat K, Shugfta H. Bacteriology and antimicrobial susceptibility of neonatal septicemia in NICU, PIMS, Islamabad- A Tertiary Care Hospital of Pakistan. Ann. Pak. Inst. Med. Sci. 2010; 6(4):191-5.
21. Ahmad A, Hussain W, Lamichhane A, Muhammad $A$, Riaz $L$. Use of antibiotics in Neonatal sepsis at neonatal unit of a Tertiary Care Hospital. Pak Paed J. $2011 ; 35(1): 3-7$.

22. Edwards MS. Postnatal infections. In: Martins F, editor. Neonatal-Perinatal Medicine. 8th ed. Philadelphia, PA: Mosby Elsevier; 2006. p. 793-804.

23. Karthikeyan G, Premkumar K. Neonatal sepsis: Staphylococcus aureus as the predominant pathogen. Indian J Pediatr 2001; 68 (8): 715-7.

24. Zaidi AK, Tikmani SS, Warraich HJ, et al. Communitybased treatment of serious bacterial infections in newborns and young infants: A randomized controlled trial assessing three antibiotic regimens. Pediatr Infect Dis J 2012; 31(7): 667-72.

\begin{tabular}{|c|c|c|c|}
\hline \multicolumn{4}{|c|}{ AUTHORSHIP AND CONTRIBUTION DECLARATION } \\
\hline Sr. \# & Author(s) Full Name & Contribution to the paper & Author(s) Signature \\
\hline 1 & Shahid lqbal & $\begin{array}{l}\text { Methodology, Data collection, } \\
\text { Proof reading. }\end{array}$ & $\therefore \rightarrow$ \\
\hline 2 & Fazal Ur Rehman & $\begin{array}{l}\text { Litearture review, Data } \\
\text { analysis,Drafting. }\end{array}$ & 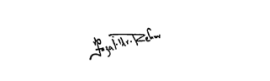 \\
\hline 3 & Waqas Ali & Methodology, Discussion. & $\cos$ \\
\hline 4 & Sanam Bano Rajper & Methodology, Discussion. & then \\
\hline
\end{tabular}

